\title{
Sex-Based Differences in Coronary and Structural Percutaneous Interventions
}

\author{
Ashley Mohadjer - Garrett Brown · Syed R. Shah • Charishma Nallapati • \\ Nida Waheed $\cdot$ Anthony A. Bavry $\cdot$ Ki Park
}

Received: April 20, 2020 / Published online: May 21, 2020

(c) The Author(s) 2020

\section{ABSTRACT}

In the current state of interventional cardiology, the ability to offer advanced therapies to patients who historically were not surgical candidates has grown exponentially in the last

Digital Features To view digital features for this article go to https://doi.org/10.6084/m9.figshare.12264233.

A. Mohadjer · G. Brown · K. Park ( $\square)$

Division of Cardiovascular Medicine, University of Florida, Gainesville, FL, USA

e-mail: ki.park@medicine.ufl.edu

S. R. Shah

Department of Internal Medicine, North Florida Regional Medical Center, University of Central Florida (Gainesville), Gainesville, FL, USA

C. Nallapati · N. Waheed

Department of Internal Medicine, University of Florida, Gainesville, FL, USA

\section{A. A. Bavry}

Division of Cardiology, Department of Internal Medicine, University of Texas Southwestern, Dallas, TX, USA

G. Brown

Division of Cardiovascular Medicine, University of South Florida, Tampa, FL, USA few decades. As therapies have expanded in complex coronary and structural interventions, the nuances of treating certain populations have emerged. In particular, the role of sexbased anatomic and outcome differences has been increasingly recognized. As guidelines for cardiovascular prevention and treatment for certain conditions may vary by sex, therapeutic interventions in the structural and percutaneous coronary areas may also vary. In this review, we aim to discuss these differences, the current literature available on these topics, and areas of focus for the future.

Keywords: Aortic valve disease; Interventional cardiology; Mitral valve disease; Percutaneous coronary intervention; Sex-related disparities; Sex-specific factors 


\section{Key Summary Points}

Why carry out this study?

More women have died from cardiovascular disease than men in recent years due to different risk factors and anatomical differences that impact therapeutic procedural indication and outcome.

Women are often underrepresented in cardiovascular trials, leading to a one-sizefits-all approach to cardiovascular care.

What are the sex-based differences in anatomy and outcomes discussed in the literature, and how does this impact percutaneous coronary and structural intervention?

\section{What was learned from the study?}

With regard to coronary intervention, female patients are observed to have increased in-hospital mortality and inhospital complications compared to men.

Sex-specific differences in major vascular complications, patient-prosthesis mismatch, and pacemaker implantation are present in patients undergoing TAVR. Differences in outcomes after mitral valve repair among sexes have not consistently demonstrated statistical significance, but may depend on etiology of the mitral valve disease.

Further study is needed to examine sexspecific differences so that we may better select therapies for patients.

\section{BACKGROUND}

Sex-related differences in the pathophysiology, treatment, and outcomes of cardiovascular diseases have been studied in greater detail in the last few decades [1]. Since the mid-1980s, in the
United States, more women have died from cardiovascular disease compared to men [2]. This is partly due to women having different anatomic and risk factor profiles relevant to procedural indications and outcomes. Additionally, women with coronary artery disease typically have worse outcomes compared to men [3]. Thus, significant sex-related disparities persist, resulting in suboptimal treatment of women. Even when multiple social and economic factors are considered such as level of education, income, and access to care, this inconsistency continues to be significant [4]. Although many reasons have been elucidated to explain this disparity, much remains unclear. Some of the sex-related differences in outcomes may be partially explained by variation in the pathophysiology of certain diseases. For example, women with acute coronary syndrome are less likely to have significant obstructive coronary artery disease, but are more likely to have plaque erosion and thrombus formation when compared to men with similar symptoms [5-7]. It appears that the less frequent presence of obstruction may be related to different patterns of atherosclerosis. Analyses have shown that coronary vessels in women appear to have a more diffuse atherosclerotic disease pattern with involvement of the entire circumference of the artery [6]. Thus, coronary arteries appear more "normal" at the time of angiography in nearly $50 \%$ of women, without evidence of flow-limiting stenosis [8]. Thus, the approach to coronary intervention for stenoses that are significant may be different for women versus men based on the pattern of atherosclerosis.

Additionally, some of the differences in outcomes may be related to variation in coronary anatomy by sex. Coronary vessels in women on average are smaller than those of men, up to $10 \%$ smaller, independent of body size $[9,10]$. Studies looking at major epicardial coronary diameters on cardiac computed tomography imaging in patients with minimal coronary artery calcium (scores $<100$ Agatston score) found significantly smaller vessel diameter in women compared to men. This difference persisted after adjustment for body mass index, body surface area, age, and left ventricular mass [11]. It has been suggested that sex hormones 
may play a role in the size variation due to their impact on arterial remodeling [10]. Additionally, female vessels may show impaired vasodilator response, though this is somewhat controversial $[9,10]$. They may also have increased vascular stiffness compared to men $[9,10]$. This can affect hemodynamic assessment of coronary lesions, which can have implications for long-term outcomes of percutaneous coronary intervention (PCI).

Finally, we must also be aware of the differences regarding female representation in evidence-based therapies and interventions. While the proportion of women undergoing certain interventions varies, women continue to be underrepresented in cardiovascular trials and on average comprise only $25 \%$ of clinical investigation [12]. Fortunately, awareness of this important issue has increased, and more research is being done to understand sex-specific aspects of care. A position piece published in 2019 highlighted that many sex-specific differences are unveiled in post hoc analyses or systematic reviews. The authors suggested that differences in risk/decision-making, communication, and investigator engagement may be among the reasons for underrepresentation of women in cardiovascular trials, and recommend in-depth analysis of social and behavioral barriers to better engage female trial participants [13]. While the relevance of sex-based differences does depend on the exact condition or intervention, consideration of these factors is essential to avoid treating patients according to a "one size fits all" strategy. In this review, we aim to discuss these sex-specific differences, the current literature available on these issues, and areas to focus on in the future. We also highlight anatomic structural differences between women and men which may affect structural and coronary interventions (Fig. 1). This review is based on previously conducted studies and does not contain any studies with human participants or animals performed by any of the authors.

\section{PERCUTANEOUS CORONARY INTERVENTIONS}

\section{Stents}

Since the era of Andreas Gruentzig and initial balloon angioplasty, the field of PCI has

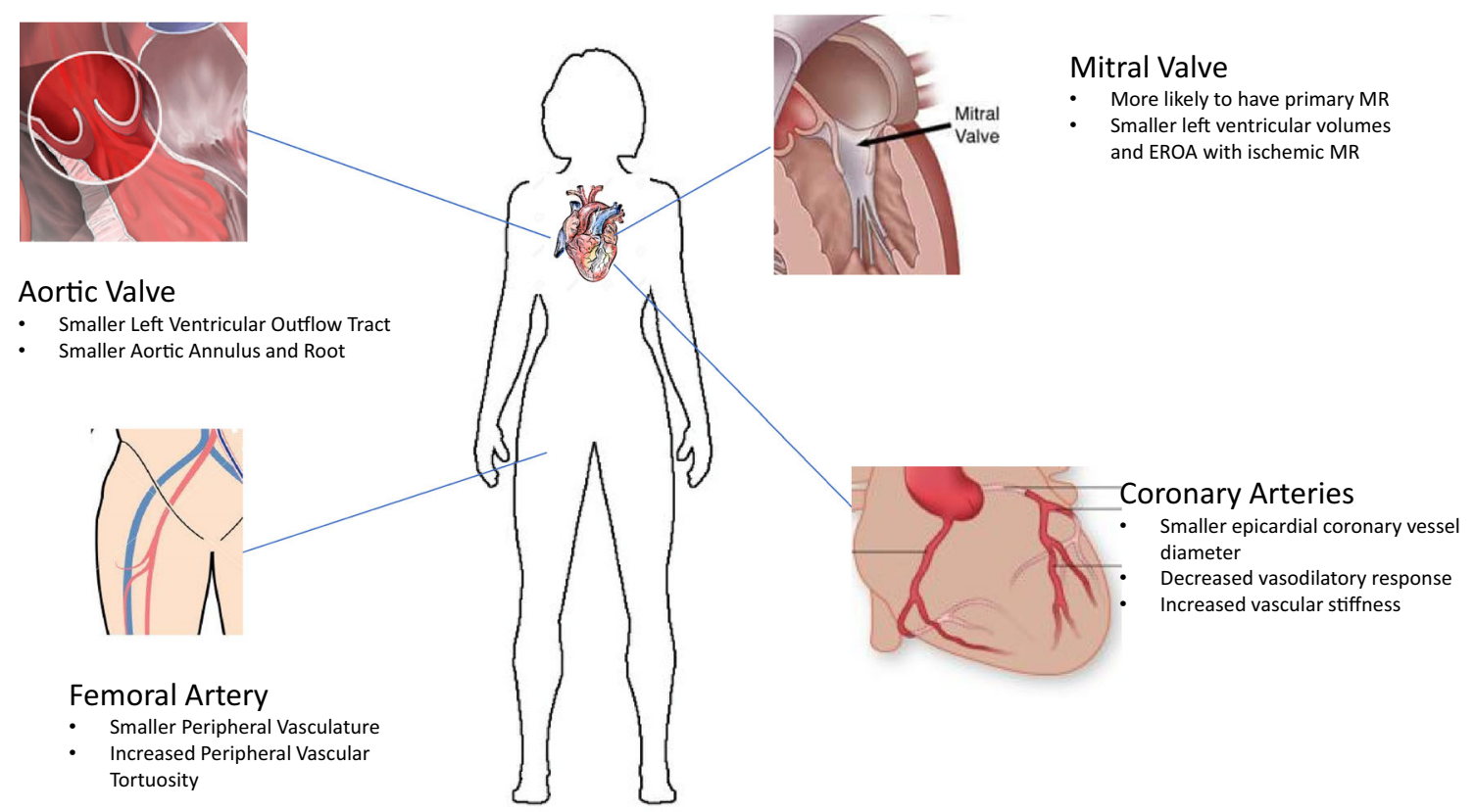

Fig. 1 Anatomic features in women affecting coronary and structural interventions. $M R$ mitral regurgitation; EROA effective regurgitant orifice area 
dramatically changed our ability to treat patients with obstructive coronary disease. Contemporary studies comparing outcomes by sex have shown mixed results with female sex being associated with variable mortality rates [14-16]. However, these studies did not account for non-traditional cardiac risk factors including depression, which maybe more prevalent in females and is shown to be associated with adverse outcomes in cardiovascular patients [17]. Many studies are outdated in the current era where routine use of prasugrel and ticagrelor is common. Hence, whether sex-based differences in outcomes still exist in contemporary practice is still questionable.

Some aspects of PCI in the female sex have been better studied in the literature. The female sex has been consistently identified as a predictor of major bleeding after PCI, which may be explained by several factors [18-20]. This increased risk for women may be due to variation in platelet pathophysiology and response to different antiplatelet therapies owing to the sex-based differences in platelet function [21-24]. Differences in patient age, drug safety profile, or comorbidities associated with bleeding may also explain this elevated risk $[14,25,26]$. While radial access is more commonly performed in both male and female patients, the rate of conversion to a femoral approach is more common in women, and may account for the increased risk of bleeding [19]. Recent data in general show that bivalirudin reduced bleeding compared to heparin plus a glycoprotein IIb/IIIa inhibitor. On the other hand, prasugrel reduced ischemic outcomes but at the cost of more bleeding compared to clopidogrel [27-30].

Now in our second generation of drug-eluting stents (DES), complications of stent thrombosis and in-stent restenosis (ISR) have declined significantly with new designs and drug-elution systems continuing to emerge on the market. In everyday practice, many of these stents are used off label in calcified, tortuous, and small-caliber coronary vessels. As mentioned previously, women generally have smaller-caliber vessels along with smaller left ventricular dimensions [10]. It is generally accepted that the risk of stent thrombosis and ISR increases in smaller diameter stents. As stent technology advances to reduce short- and long-term complications, it is unknown whether these adverse outcomes are affected by sex. There has been improved insight into this subject from work supported through the Society for Cardiovascular Angiography and Intervention (SCAI) [31]. As part of their women's initiative, Women in Innovation and Drug-Eluting Stents (WIN-DES) was created to gather and analyze data regarding PCI in women [31]. A large multicentered registry sponsored by WIN-DES assessed differences in outcomes of DES in women [32]. Since women have been traditionally underrepresented in clinical trials, the authors performed a collaborative analysis across 26 randomized control trials [32]. The authors found that women who underwent PCI were older, had lower ejection fractions, and had a higher incidence of prior myocardial infarction and diabetes [32]. These women also had more complex disease with multi-vessel obstruction and calcified lesions [32]. At 3-year follow-up, the use of DES was associated with reduction in major adverse cardiovascular events compared to earlier generations, and lower rates of stent thrombosis. Based on available data, outcomes with DES appear to be comparable to those in men.

Although stent design/materials and drugelution properties have progressed significantly in recent years, long-term concerns regarding residual metallic scaffolds and increased late events have continued. To counter these concerns, bioresorbable scaffolds (BRS) were designed. These are composed of a temporary scaffold designed to provide a platform for drug elution but then degrade over time with no material left behind. Studies have shown that these scaffolds fully resorb after 3 years, leaving the vessel in its native state [33]. However, the enthusiasm for these new stents has been tempered by concerns over increase in stent thrombosis, leading to limitations in use in Europe and the United States [34]. It is unclear if indications for use of BRS or long-term outcomes would differ by sex. It could be postulated that since women have smaller coronary vessel diameters, BRS may further increase the risk of stent thrombosis. However, once the scaffold is degraded there is return of native 
vasomotor function of the vessel, which is an advantage of this type of stent. Since women have more evidence of endothelial dysfunction at baseline, this property may be of particular interest [10]. Additionally, there have been limited case reports on use of BRS to treat spontaneous coronary artery dissection [35]. Although not a major indication for PCI, spontaneous dissection tends to occur more in young women who may benefit from absorption of stent scaffolding. This would allow these women to avoid potential long-term complications from residual metallic materials left behind by traditional DES. Overall, it is unclear if BRS technology would be beneficial in women, though it deserves further study [36].

Outcomes related to PCI differ among men and women as well. A recent study looking at PCI in 6 million patients in the United States found that women were more likely to suffer inhospital mortality and in-hospital complications compared to men [19]. Some of the sexspecific differences were attributed to bleeding risk as previously discussed, but others remain unclear. It appeared that women consistently had a $20 \%$ greater risk of in-hospital mortality and overall adverse events compared to men, even after adjustment for comorbid burden and clinical characteristics [19]. Furthermore, a study looking at women who underwent PCI for ST elevation myocardial infarction also showed $20 \%$ higher age-adjusted risk of death and ischemic cardiac or cerebrovascular events compared to men, despite identical PCI success rates [37]. Women receiving PCI for stable coronary artery disease or non-ST elevation myocardial infarction, however, were not found to have different outcomes compared to their male counterparts [37]. Finally, there appear to be differences in outcomes between sexes in patients with multivessel coronary artery disease. A recent meta-analysis assessing PCI versus coronary artery bypass graft (CABG) revascularization showed that women had a worse overall composite outcome with PCI compared to men, with a hazard ratio of 1.31 (95\% CI $1.05-1.63, p<0.017)$ [38]. While only six of the 15 randomized controlled trials in the meta-analysis included sex-based data on composite outcomes of all-cause mortality, myocardial infarction, and/or stroke, this study again highlights the need for more data on sexbased outcomes in revascularization.

In conclusion, extensive data in the literature suggests that women undergoing PCI are usually older, have lower functional status, more comorbidities, and are more often depressed compared to men. Women are consistently at higher risk of bleeding, even after multivariable adjustment. Extensive data suggests that women are not only at higher risk of more severe bleeding than men, but also are more likely to have post-discharge bleeding not brought to their physician's attention. This may contribute to the observed increased risk of inhospital mortality and in-hospital complications in female patients, though more devoted study is needed.

\section{Chronic Total Occlusion (CTO)}

Interest in more complex PCI such as chronic total occlusion (CTO) interventions has grown tremendously in recent decades. Driven by rapid expansion of new technologies, patients now have options available other than coronary bypass for CTO lesions that were previously felt to be untreatable. As this area of PCI expands, operators should be cognizant of potential differences in sex-based outcomes. A recent study by Sharma et al. retrospectively assessed a large database from the United Kingdom of CTO PCI [39], and found that overall complication rates of CTO PCI were higher in women. This included coronary perforation, bleeding, and contrast-induced nephropathy. In general, female patients were again older than their male counterparts. Women had lower rates of prior bypass surgery, less procedure time, and reduced contrast load compared to men. The difference in success rates observed between sexes in CTO PCI may be explained by the presence of collateral arteries, which are important in determining the approach to CTO PCI. While there is no clear evidence citing differences in the presence or robustness of collateral vessels in females, a difference could be plausible based on known differences in microcirculatory function with regard to 
decreased vasodilatory response and overall higher rates of microvascular dysfunction in women [9].

More recently, a meta-analysis was published showing that sex was not an independent risk factor for major adverse cardiovascular events or procedural success for patients with CTO lesions who underwent PCI [40]. However, women comprised only $14-23.7 \%$ of the populations in those studies that were included in the metaanalysis (8811 women vs. 23,496 men) despite similar prevalence of CTO lesions [40]. This again may imply that women are underrepresented in CTO trials and highlights the need for further inclusion of women, and further study of sex-based differences in outcomes in patients with CTO.

\section{STRUCTURAL INTERVENTIONS}

\section{Aortic Valve Disease}

Aortic stenosis (AS) remains an important cause of morbidity and mortality in elderly populations, and is considered the most prevalent form of valvular disease within elderly Western populations [41]. Through the advent of transcatheter-based technology, many patients who were not surgical candidates can now be treated with minimally invasive procedures. Although a less invasive procedure, the indications and differences in outcomes for transcatheter aortic valve replacement (TAVR) based on sex need to be considered.

\section{Pathophysiology}

The main pathology of AS is valve leaflet calcification. Lipid infiltration, aberrant extracellular matrix remodeling, and extensive valvular fibrosis may also be factors contributing to the thickening and decreased mobility of the aortic valve leaflets in aortic stenosis [42]. There are sex-specific differences in the level of valvular fibrosis and dense connective tissue, as well as the degree of hemodynamic stenosis severity. Women may present with symptomatic, severe AS with less calcium but more fibrosis than men, suggesting that the pathobiology for development and progression of AS may differ by sex [43].

\section{Epidemiology}

The reported prevalence of AS among the elderly population is $12.4 \%$, while the prevalence of severe AS in the same population is $3.4 \%$. Under the current indications, approximately 290,000 elderly patients with severe AS are TAVR candidates [41]. However, there continues to be a disparity between male and female sex in diagnosis, treatment, and management of the disease. Extensive echocardiographic data shows that men are twice as likely to develop aortic stenosis compared to women [44]. Several studies have reported a higher utilization of surgical aortic valve replacement (SAVR) in men compared to women [45-48]. This may be because women with aortic stenosis had unfavorable preoperative baseline characteristics, and were thus less likely to be referred for surgical treatment [44]. Interestingly, this disparity in referral for valve replacement is not seen with the current TAVR practice $[49,50]$. Since TAVR became commercially available in the United States in 2011, women have been referred more often for TAVR compared to men [49]. Women are often older when they develop symptomatic AS, which may explain the increase in TAVR referral initially [51].

\section{Differences in Anatomy/Surgical Technique}

When assessing a patient for possible SAVR or TAVR, both anatomic and clinical considerations, such as surgical risk, should be considered. The choice of access site and valve type depends on several factors, including presence of peripheral disease and aortic arch anatomy. Specifically, there is a higher likelihood of aortic valve area-gradient discordance due to smaller left ventricular outflow tract dimensions and more frequent paradoxical low-flow, low-gradient severe aortic stenosis in women compared to men [52]. Buellesfeld et al. evaluated TAVRrelated multi-detector computed tomography imaging findings among 97 women and 80 men with severe symptomatic aortic stenosis and found smaller annular and left ventricular outflow tract dimensions in women, but similar 
ascending aortic dimensions [53]. The smaller aortic annuli in women are associated with use of smaller transcatheter heart valves compared to men. Although implications of small valve size historically relate to some elderly women falling out of range of available devices, this has become less of problem since the induction of smaller transcatheter heart valves sizes, as well as self-expanding and balloon-expandable platforms. Patients with a smaller annulus had lower rates of severe prosthetic valve regurgitation compared to patients with a large annulus [52]. Proper assessment of the aortic annulus is important for valve sizing. The width of the sinuses of Valsalva and the height of the coronary arteries, specifically the left main, are crucial for proper assessment as well. Women generally have smaller body surface areas compared to men, therefore these aortic root structures tend to differ in size as well [54]. The smaller vessel size in women is not limited to the aortic arch; women have smaller diameter peripheral vessels that are suboptimal or prohibitive for femoral access [1].

Given the innumerable differences discussed above, thoughtful consideration should be given to procedural technique. Specifically, the access site (transfemoral, transaxillary, transapical, or direct aortic access) and the use of self-expanding or balloon-expanding valves should be given extra attention. Lack of appreciation of these differences (valve size, height of coronary arteries) can lead to suboptimal valve implantation, leading to catastrophic complications (Table 1) such as coronary obstruction

Table 1 Differences in complications post-transcatheter aortic valve replacement

\section{Women}

$\downarrow$ Pacemaker implantation

$\uparrow$ Coronary obstruction

$\uparrow$ Likelihood of patient-prosthesis mismatch

$\uparrow$ Peripheral vascular complications (i.e., bleeding)

$\uparrow$ Annular rupture or annular rupture that are known to occur more frequently in women [54].

\section{Review of Outcomes}

The landmark TAVR trials assessed outcomes in patients who were felt to have prohibitive risk for SAVR. Since safety data have shown equivalent outcomes, more recent studies have focused on low and intermediate-risk groups. Along the lines of safety, there is evidence of notable differences in adverse outcomes based on sex. Post-procedurally, women have demonstrated increased risk of annular rupture, coronary obstruction, peripheral vascular complications, and possible risk of patient-prosthesis mismatch [52]. In contrast, the need for permanent pacemaker implantation post-TAVR was lower in women compared to men (Table 1) [51].

Patient-Prosthesis mismatch Patient-prosthesis mismatch occurs when the effective orifice area of an inserted prosthetic valve is too small relative to body size, resulting in higher than expected gradients in otherwise normally functioning prosthetic valves. Patient-prosthesis mismatch is a concern in patients with small aortic annulus size undergoing SAVR but has not been problematic with TAVR. Recent studies have shown that despite the need for smaller valve sizes in women, they do not appear to be at increased risk of patient-prosthesis mismatch [55]. A recent trial performed by Popma et al. found that in patients with severe aortic stenosis who were low surgical risk, TAVR with a selfexpanding supra-annular bioprosthesis was not inferior to SAVR with respect to death from any cause at 24 months [56]. This suggests an increased utility of TAVR in those who are surgical candidates, but who also have smaller annular dimensions [57]. Extrapolating further, this suggests that TAVR should be the preferred intervention in women with severe AS [55]. Further studies are needed to directly compare TAVR versus SAVR in this cohort, however, to assess possible impact of patient-prosthesis mismatch on long-term clinical outcomes.

Coronary obstruction risk Women also have a higher risk of coronary occlusion/obstruction due to lower coronary heights and smaller sinuses of Valsalva [10]. These dimensions are 
inversely related to left main obstruction postimplantation [58]. A higher proportion (> 80\%) of patients who developed coronary obstruction were women despite equal sex representation in their registries [58]. In such cases, novel techniques such as BASILICA, a technique involving intentional laceration of the native or bioprosthetic leaflet to prevent iatrogenic coronary artery obstruction, may be considered to reduce the risk of coronary obstruction.

Permanent pacemaker implantation Permanent pacemaker placement is a known risk of TAVR, with risk related to valve type and underlying conduction disease. A 2019 study looking at sex differences in outcomes among the CENTER collaboration data for trans-femoral TAVR procedures noted that the need for permanent pacemaker implantation was lower for females compared to males (12.2 vs. $16.7 \%$, RR $0.7,95 \%$ CI $0.7-0.8 \%, p<0.001)$ [51]. This difference was seen with both self-expandable and balloon-expandable valves, though pacemaker implantation rates were higher in both sexes among the self-expandable valve group [51]. This finding may be due to anatomical and sizing discrepancies seen among the sexes, but warrants further investigation to characterize the mechanism.

Peripheral vascular complications The overall risk of peripheral vascular complications has declined with advances in technology allowing the use of lower-profile delivery systems. However, this risk has not been eliminated and is known to vary by sex, with women having more vascular complications (6-20\% vs. $2-14 \%$ ) and higher bleeding rates $(10-44 \%$ vs. $8-25 \%)$ compared to their male counterparts compared to their male counterparts, see Table 3 [59]. A 2019 study looking at the CENTER collaboration data in transfemoral TAVR procedures also found elevated risk of bleeding in women by about $50 \%$ (6.7 vs. $4.4 \%$, RR $1.5 ; 95 \%$ CI $1.3-1.8, p<0.001)$ [51]. Interestingly, bleeding risk appeared to correlate inversely with body mass index (BMI) in females (lowest BMI bleeding rate $7.7 \%$, middle BMI group $7.1 \%$, and highest BMI group 5.5\%), with no particular correlation in the male cohort [51]. These findings were true for both early and newer generation TAVR valves. Large sheath-to- femoral-artery ratio, increased vessel tortuosity, and significant vascular calcification specifically contributing to these findings [51]. Previously described differences in femoral diameter between sexes may explain the elevated rate of vascular complications in women, as they appear to undergo TAVR via transfemoral access more frequently [1]. Appropriate use of preTAVR imaging assessments of iliofemoral vasculature is therefore particularly important in women [52]. This further supports the need for more evidence on antithrombotic therapy postTAVR, as well as potential adjunctive options in those with higher bleeding risk. In late 2019, Saito et al. published a review on adjunctive antithrombotic regimens post-TAVR and found that single antiplatelet therapy (SAPT) may be safer than dual antiplatelet therapy [60]. Additionally, they suggested that an oral anticoagulant alone may be superior to oral anticoagulation plus SAPT in those patients requiring full anticoagulation. Future trials are underway that may provide clarity on this issue, and may be particularly beneficial in women who have demonstrated increased risk of bleeding [60].

Overall morbidity and mortality In a metaanalysis of 23 publications, women had fewer pre-existing co-morbidities and better survival (range of hazard ratio $[95 \%$ CI $]=0.27$ [0.09-0.84] to $0.91[0.75-1.10])$ with TAVR compared to SAVR [59]. More recent data looking at over 12,000 patients found higher baseline prevalence of hypertension and renal failure in females, but lower prevalence of common cardiovascular comorbidities like coronary artery disease, prior PCI or coronary artery bypass graft, diabetes mellitus, stroke, and peripheral arterial disease [51]. While some previous studies outline a lower mortality rate in women due to more favorable baseline characteristics and lower rates of significant paravalvular aortic regurgitation, others suggest that both sexes have similar mortality outcomes, at least in the 30-day period $[51,52,59,61]$. Overall mortality and stroke rates 30 days post-TAVR were found to be similar in males and females in the CENTER collaboration dataset, despite the increase in bleeding complications for females mentioned 
above [51]. The 30-day mortality was lower in both sexes by at least $50 \%$ over the last 10 years, with overall mortality rates between 2007 and 2018, the data collection period, decreasing further in males over time compared to females [51]. Stroke rates, however, did not change over time in either sex [51]. Outcomes of TAVR versus SAVR in women, particularly in the low-risk population, have yet to be thoroughly examined. In high-risk and inoperable patients, females may have a survival benefit of up to 2 years with TAVR compared to SAVR [62]. In similar populations in the PARTNER 3 trial, the rate of death, stroke, or re-hospitalization at 1 year was actually found to be lower with TAVR than with surgery [63]. More sex-specific analyses are needed to analyze these differences, and to help clarify conflicting evidence in the literature.

\section{Understanding Sex-Specific Factors: Insight from Registry Data in Women}

As the use of structural heart interventions has increased, so has the recognition of sex-specific characteristics and risk. This led to the creation of the Women's International Transcatheter Aortic Valve Implantation (WIN-TAVI) RealWorld Registry [64]. This was related in part to the recognition that sex-specific factors as illustrated can influence indications, outcomes, and mortality. This 19-center prospective, observational registry was created specifically to analyze data in women undergoing TAVR in North America and Europe. The registry includes a variety of endpoints including safety data and mortality, among others. Over the course of 2 years, just over 1000 women have been enrolled. The primary findings from initial analyses revealed that the women enrolled were at intermediate-high risk and had low early mortality. Pregnancy history was also collected in this cohort, specifically parity status and gestational complications. Pregnancy and adverse pregnancy conditions such as preeclampsia, gestational diabetes, and premature birth are known to be associated with increased long-term cardiovascular risk in women [65]. While $70 \%$ of the women enrolled had been pregnant, less than 5\% suffered a pregnancy complication. History of pregnancy was predictive of early safety endpoints after TAVR. These intriguing findings stress the need for sexspecific history taking and risk assessment in subjects enrolled in registries or clinical trials.

\section{Mitral Valve Disease}

Mitral regurgitation (MR) is the second leading cause of valvular heart disease in US, behind AS [66]. The current standard of care is surgical repair or replacement of the mitral valve. The indications for mitral valve repair or replacement include severe symptomatic primary MR, or asymptomatic MR in conjunction with left ventricular dysfunction (as noted by an ejection fraction of $30-60 \%$ ), new-onset atrial fibrillation, or pulmonary hypertension. However, there are limited studies directly comparing surgical repair versus replacement.

\section{Pathophysiology}

MR is classified into two broad categories by etiology: primary or secondary. Primary regurgitation refers to valvular pathology intrinsic to the valve or valve apparatus. Primary MR can result from myxomatous changes such as mitral valve prolapse, collagen vascular disease, papillary muscle dysfunction, mitral annular calcification, trauma, rheumatic heart disease, endocarditis, or spontaneous chordal rupture. Secondary $\mathrm{MR}$ is a catch-all category that encompasses anything not classified as primary. More specifically, this involves extra-valvular dysfunction that directly results in dysfunction of the mitral valve, such as left atrial or left ventricular dilation. Secondary $\mathrm{MR}$ is often a result of advanced stages of ischemic, dilated, or hypertrophic cardiomyopathy. Once valvular disease is severe, both primary and secondary MR have a poor prognosis.

\section{Epidemiology}

There are more than 40,000 mitral valve surgeries performed annually in the USA alone [67]. However, $50 \%$ of the population eligible for surgery based on their valve criteria are denied due to older age, comorbidities, or reduced ejection fraction. Traditionally, those denied surgery were given medical therapy alone. 
Fortunately, percutaneous mitral valve therapy has been rapidly emerging as an alternative to both surgical and medical therapy. Currently, the only mainstream alternative available is the MitraClip device, a large clip inserted percutaneously that grasps the anterior and posterior leaflets of the mitral valve to reduce MR. This has only been available since 2013, and questions remain as to who should undergo the clip procedure, and when it should be performed.

\section{Review of Outcomes}

One of the first studies to compare mitral valve repair versus replacement included 698 prospective matched case-control patients and published in 2003 [68]. In the repair group, both length of stay (9.5 days vs. 12.3 days) and in-hospital mortality (4.3 vs. $6.9 \%$ ) were significantly lower than in replacement patients. At 5 and 10 years, the survival of patients who underwent repair versus replacement were improved (82 vs. $72 \%$ and 62 vs. $46 \%$, respectively). Other studies supported these findings as well, demonstrating that preservation of the subvalvular apparatus, annulus, and mitral leaflets allows improvement of ventricular function after repair rather than replacement [69-72].

The landmark trial for MitraClip was EVEREST I [73], which demonstrated that the procedure could be safely performed in patients and improve MR [73]. In EVEREST I, women comprised $38 \%$ of the group studied, and sex was evaluated as a subgroup to assess for a risk factor contributing to the endpoint of survival, mitral valve surgery or reoperation, and $3+$ or $4+\mathrm{MR}$ at 5 years. Female sex was not demonstrated to be statistically different in the analysis [73]. This study was followed with EVEREST II which attempted to demonstrate the efficacy of MitraClip by comparing it with the standard of care: surgical repair or replacement. Both EVEREST I and EVEREST II data showed that surgical repair was superior to MitraClip before hospital discharge [73, 74]. EVEREST II showed that there were similar rates of reduced MR at 12 and 24 months of follow-up, and indicated percutaneous treatment was associated with increased safety, improved left ventricular dimensions, and improved quality of life. It is important to note that the patient population was deemed relatively low risk as demonstrated by all patients enrolled being candidates for either surgery or percutaneous therapy. Also, this was a first-in-class device and technique. At 5-year follow-up, EVEREST II patients with grade $3+$ or $4+$ MR who received percutaneous repair versus surgical repair were found to have a reduced rate $(44.2 \%$ versus $64.3 \%$, $p=0.01$ ) of the composite endpoint (freedom from death, surgery, or $3+$ or $4+$ mitral regurgitation). Thus, high-risk patients were identified to benefit from percutaneous therapy over conventional surgery [74]. Subsequent studies focused on this high-risk population and were followed in the EVEREST II High Risk Registry. These patients had a Society of Thoracic Surgeons expected procedural mortality rate $>12 \%$. Women comprised $46 \%$ of patients in this registry but there was no significant difference noted between sexes with regard to outcome [74]. However, all patients did show a substantial improvement in heart failure symptoms and survival benefit, with fewer overall hospitalizations [74].

The COAPT trial was another more recent study looking at secondary MR in heart failure patients. Women comprised $36 \%$ of the study population overall, which was divided into medical therapy alone (control) and medical therapy plus MitraClip (device) groups [75]. Overall in patients who remained symptomatic on maximal medical therapy, those who underwent transcatheter mitral valve repair with MitraClip demonstrated lower all-cause mortality at 24 months and had a lower rate of heart failure hospitalizations [75]. In subgroup analysis looking at 24-month all-cause mortality, both men and women showed similar outcomes that favored the device group, with HR 0.59 (95\% CI $0.42-0.82)$ and 0.61 (95\% CI 0.35-1.05), respectively [75]. Similar outcomes again were seen in men and women when looking at hospitalization due to heart failure over a 24-month period [75].

Another important trial, the MITRA-FR study, also looked at secondary MR in heart failure patients. In contrast to COAPT, the MITRA-FR trial found no significant difference in mortality or heart failure hospitalizations at 
12 months between the control (medical therapy) and intervention (medical therapy with percutaneous mitral valve repair) groups [76]. Interestingly in subgroup analysis of the primary endpoint, men were found to have an odds ratio of 1.30 (95\% CI 0.7-2.10) suggesting benefit with medical therapy alone. Women were found to have more benefit with percutaneous mitral valve repair with an odds ratio of 0.90 (95\% CI 0.4-2.30). However, this difference between sexes was not statistically significant $(p=0.55)$ [76]. A contributing factor to these findings may be that the majority of people in both study groups were men, representing $78.9 \%$ and $70 \%$ of control and intervention cohorts, respectively [76].

\section{Understanding Sex-Specific Factors and Differences}

MitraClip was approved for use in 2008 in Europe and 2013 in the USA for high-risk patients with degenerative MR [77]. To date, surgical repair remains the gold standard for severe mitral regurgitation. ACCESS-EU was a registry that used the European System for Cardiac Operative Risk Evaluation (EuroSCORE) instead of Society of Thoracic Surgeons. ACCESS-EU showed that women experienced similar safety and efficacy results as their male counterparts but had higher rates of discharge to skilled nursing facilities [77]. Two hundred and five women and 362 men had similar baseline risk scores [78]. Women had higher rates of primary disease (32 vs. 18\%) and were more likely to require only one clip (72 vs. 54\%) but unfortunately had a similar length of stay in the intensive care unit $(\sim 2.6$ days $)$ and overall length of stay $(8.0 \pm 6.9$ days $)$ compared to men. Thirty-day and 12-month safety results, 12-month efficacy, and 12-month survival were similar between sexes. However, women were more likely to be discharged to skilled nursing facilities ( 25 vs. $15 \%)$ rather than home.

Transcatheter Valve Treatment and Sentinel Pilot Registry in Europe (TCVT-EU) and Transcatheter Mitral Valve Interventions (TRAMI) were two registries similar to EVEREST HRR and ACCESS-EU $[79,80]$. TRAMI is currently the largest real-world cohort of patients and enrolled 1,064 patients to follow them at 1, 3, and
5 years [79]. TRAMI demonstrated that traditional risk factors for conventional cardiac mitral valve surgery such as female sex, advanced age, severely reduced left ventricular ejection fraction, and high risk score were not predictive for mortality or major complication rates [79]. However, further studies have questioned these results.

Getting Reduction of Mitral Insufficiency by Percutaneous Clip Implantation (GRASP) consisted of 171 patients, of which 65 were women [81]. The primary safety endpoint was incidence of major adverse events at 30 days, and the primary efficacy endpoint was freedom from death, surgery for mitral valve dysfunction, or grade $3+$ or higher mitral regurgitation at 12-month follow-up [80]. The primary safety endpoint was observed in four men $(3.8 \%)$ and four women (6.2\%). Both groups enjoyed remarkable reduction in mitral regurgitation post-procedure as well as left ventricle reverse remodeling. However, despite overall New York Heart Association (NYHA) functional class at 30 days and 12 months being similar between men and women, more women were in NYHA functional class III, leading to a trend in better improvement for men compared to women over time $(p=0.083)$.

More recently, the first randomized control trial was conducted to study sex-based differences in outcomes after mitral valve replacement versus repair for severe ischemic MR [82]. Published in 2019, this study followed patients with 96 (38.2\%) women for 2 years and demonstrated that women had smaller left ventricular volumes and effective regurgitant orifice (EROA) areas although greater EROA/left ventricular end-diastolic volume ratios. At 2 years, women had higher rates of all-cause mortality (27.1 vs. $17.4,95 \%$ CI $1.05-3.26)$ and major adverse cardiovascular and cerebrovascular events (49 vs. 38.1\%, 95\% CI 1.06-2.37). They also reported worse quality of life and functional status compared to men. It is important to note that although there was no significant difference in age between men and women, women were more likely to have comorbidities like diabetes mellitus, hypertension, chronic kidney disease, and thyroid disease. 
The fundamental difference from the data thus far is the distinction between primary vs. secondary regurgitation. EVEREST II consisted of $73 \%$ primary mitral regurgitation, whereas EVEREST II HRR/REALISM, GRASP, ACCESS-EU, TCVT-EU, and TRAMI all had at least 70\% functional/secondary MR. Unfortunately, more data is needed to further elucidate factors contributing to sex differences in outcomes of patients undergoing percutaneous mitral valve therapy.

\section{FUTURE DIRECTIONS}

As the field of interventional cardiology continues to expand, understanding the role of sexbased differences in both coronary and structural realms will continue to be of utmost importance. Much of the initial data analyzing sex-based differences in TAVR outcomes has been generated from the study of early generation devices. As the technology continues to change, this may have implications for equalizing the outcomes. For instance, recent data assessing outcomes from the most recent PARTNER 2 S3 trial assessing the SAPIEN 3 valve included lower-risk patients compared to initial studies. The authors found no difference in sexbased outcomes as opposed to earlier reports of survival and stroke [83]. Additionally, as the safety of complex structural interventions continues to improve, many of these procedures currently considered only for the highest-risk patients will be made available to lower-risk patients. As such, whether sex-based differences play a role in younger patients remains to be seen. Additionally, long-term data will be more readily available both in the current population of treated patients as well as younger patients with extended follow-up. Another important area to focus on is advocacy for more inclusion of women in cardiovascular device trials. Women have been historically underrepresented in device trials for a variety of reasons. Initiatives such as those through SCAI-WIN to promote recruitment of women will be crucial in translating advancements in medical knowledge equally to both sexes.

\section{ACKNOWLEDGEMENTS}

Funding. No funding or sponsorship was received for this study or the journal's rapid service publication fee.

Authorship. All named authors meet the International Committee of Medical Journal Editors (ICMJE) criteria for authorship for this article, take responsibility for the integrity of the work as a whole, and have given their approval for this version to be published.

Disclosures. Author Garrett Brown changed his affiliation during the completion of the manuscript to University of South Florida in Tampa, FL. Ashley Mohadjer, Syed R. Shah, Charishma Nallapati, Nida Waheed, Anthony A. Bavry, and Ki Park have nothing to disclose.

Compliance with Ethics Guidelines. This article is based on previously conducted studies and does not contain any studies with human participants or animals performed by any of the authors.

Data Availability. Data sharing is not applicable to this article as no datasets were generated or analyzed during the current study.

Open Access. This article is licensed under a Creative Commons Attribution-NonCommercial 4.0 International License, which permits any non-commercial use, sharing, adaptation, distribution and reproduction in any medium or format, as long as you give appropriate credit to the original author(s) and the source, provide a link to the Creative Commons licence, and indicate if changes were made. The images or other third party material in this article are included in the article's Creative Commons licence, unless indicated otherwise in a credit line to the material. If material is not included in the article's Creative Commons licence and your intended use is not permitted by statutory regulation or exceeds the permitted use, you will need to obtain permission directly from the copyright holder. To view a copy of this licence, 
visit http://creativecommons.org/licenses/bync/4.0/.

\section{REFERENCES}

1. O'Connor SA, Morice MC, Gilard M, Leon MB, Webb JG, Dvir D, et al. Revisiting sex equality with transcatheter aortic valve replacement outcomes: a collaborative, patient-level meta-analysis of 11,310 patients. J Am Coll Cardiol. 2015;66(3):221-8.

2. Kochanek KD, Murphy SL, Xu J, Tejada-Vera B. Deaths: final data for 2014. Natl Vital Stat Rep. 2016;65(4):1-122.

3. Graham G. Acute coronary syndromes in women: recent treatment trends and outcomes. Clin Med Insights Cardiol. 2016;10:1-10.

4. Cook NR, Paynter NP, Eaton CB, Manson JE, Martin LW, Robinson JG, et al. Comparison of the Framingham and Reynolds Risk scores for global cardiovascular risk prediction in the multiethnic Women's Health Initiative. Circulation. 2012;125(14):1748-56.

5. Bugiardini R, Bairey Merz CN. Angina with "normal" coronary arteries: a changing philosophy. JAMA. 2005;293(4):477-84.

6. Pepine CJ, Ferdinand KC, Shaw LJ, Light-McGroary KA, Shah RU, Gulati $M$, et al. Emergence of nonobstructive coronary artery disease: a woman's problem and need for change in definition on angiography. J Am Coll Cardiol. 2015;66(17): 1918-33.

7. Reynolds $\mathrm{HR}$, Srichai $\mathrm{MB}$, Iqbal $\mathrm{SN}$, Slater JN, Mancini GB, Feit F, et al. Mechanisms of myocardial infarction in women without angiographically obstructive coronary artery disease. Circulation. 2011;124(13):1414-25.

8. Chokshi NP, Iqbal SN, Berger RL, Hochman JS, Feit F, Slater JN, et al. Sex and race are associated with the absence of epicardial coronary artery obstructive disease at angiography in patients with acute coronary syndromes. Clin Cardiol. 2010;33(8): 495-501.

9. Han SH, Bae JH, Holmes DR Jr, Lennon RJ, Eeckhout E, Barsness GW, et al. Sex differences in atheroma burden and endothelial function in patients with early coronary atherosclerosis. Eur Heart J. 2008;29(11):1359-69.

10. Pepine CJ, Kerensky RA, Lambert CR, Smith KM, von Mering GO, Sopko G, et al. Some thoughts on the vasculopathy of women with ischemic heart disease. J Am Coll Cardiol. 2006;47(3 Suppl): S30-S3535.

11. Taqueti VR. Sex differences in the coronary system. Adv Exp Med Biol. 2018;1065:257-78.

12. Stramba-Badiale M, Fox KM, Priori SG, Collins P, Daly C, Graham I, et al. Cardiovascular diseases in women: a statement from the policy conference of the European Society of Cardiology. Eur Heart J. 2006;27(8):994-1005.

13. Ghare MI, Chandrasekhar J, Mehran R, Ng V, Grines C, Lansky A. Sex disparities in cardiovascular device evaluations: strategies for recruitment and retention of female patients in clinical device trials. JACC Cardiovasc Interv. 2019;12(3):301-8.

14. Alexander KP, Chen AY, Roe MT, Newby LK, Gibson CM, Allen-LaPointe NM, et al. Excess dosing of antiplatelet and antithrombin agents in the treatment of non-ST-segment elevation acute coronary syndromes. JAMA. 2005;294(24):3108-16.

15. Cowley MJ, Mullin SM, Kelsey SF, Kent KM, Gruentzig AR, Detre KM, et al. Sex differences in early and long-term results of coronary angioplasty in the NHLBI PTCA Registry. Circulation. 1985;71(1): $90-7$.

16. Vakili BA, Kaplan RC, Brown DL. Sex-based differences in early mortality of patients undergoing primary angioplasty for first acute myocardial infarction. Circulation. 2001;104(25):3034-8.

17. Meijer A, Conradi HJ, Bos EH, Thombs BD, van Melle JP, de Jonge P. Prognostic association of depression following myocardial infarction with mortality and cardiovascular events: a meta-analysis of 25 years of research. Gen Hosp Psychiatry. 2011;33(3):203-16.

18. Mehran R, Pocock SJ, Nikolsky E, Clayton T, Dangas $\mathrm{GD}$, Kirtane AJ, et al. A risk score to predict bleeding in patients with acute coronary syndromes. J Am Coll Cardiol. 2010;55(23):2556-66.

19. Potts J, Sirker A, Martinez SC, Gulati M, Alasnag M, Rashid M, et al. Persistent sex disparities in clinical outcomes with percutaneous coronary intervention: insights from 6.6 million PCI procedures in the United States. PLoS ONE. 2018;13(9):e0203325.

20. Subherwal S, Bach RG, Chen AY, Gage BF, Rao SV, Newby LK, et al. Baseline risk of major bleeding in non-ST-segment-elevation myocardial infarction: the CRUSADE (Can Rapid risk stratification of Unstable angina patients Suppress ADverse outcomes with Early implementation of the ACC/AHA Guidelines) Bleeding Score. Circulation. 2009;119(14):1873-82. 
21. Duvernoy CS, Smith DE, Manohar P, Schaefer A, Kline-Rogers E, Share D, et al. Gender differences in adverse outcomes after contemporary percutaneous coronary intervention: an analysis from the Blue Cross Blue Shield of Michigan Cardiovascular Consortium (BMC2) percutaneous coronary intervention registry. Am Heart J. 2010;159(4):677-83.

22. Fath-Ordoubadi F, Barac Y, Abergel E, Danzi GB, Kerner A, Nikolsky E, et al. Gender impact on prognosis of acute coronary syndrome patients treated with drug-eluting stents. Am J Cardiol. 2012;110(5):636-42.

23. Jacobs AK, Johnston JM, Haviland A, Brooks MM, Kelsey SF, Holmes DR Jr, et al. Improved outcomes for women undergoing contemporary percutaneous coronary intervention: a report from the National Heart, Lung, and Blood Institute Dynamic registry. J Am Coll Cardiol. 2002;39(10):1608-14.

24. Singh M, Rihal CS, Gersh BJ, Roger VL, Bell MR, Lennon RJ, et al. Mortality differences between men and women after percutaneous coronary interventions. A 25-year, single-center experience. J Am Coll Cardiol. 2008;51(24):2313-20.

25. Greenberg MA, Mueller HS. Why the excess mortality in women after PTCA? Circulation. 1993;87(3):1030-2.

26. Manoukian SV. Predictors and impact of bleeding complications in percutaneous coronary intervention, acute coronary syndromes, and ST-segment elevation myocardial infarction. Am J Cardiol. 2009;104(5 Suppl):9C-15C.

27. Kinnaird TD, Stabile E, Mintz GS, Lee CW, Canos DA, Gevorkian N, et al. Incidence, predictors, and prognostic implications of bleeding and blood transfusion following percutaneous coronary interventions. Am J Cardiol. 2003;92(8):930-5.

28. Stone GW, McLaurin BT, Cox DA, Bertrand ME, Lincoff AM, Moses JW, et al. Bivalirudin for patients with acute coronary syndromes. $\mathrm{N}$ Engl J Med. 2006;355(21):2203-16.

29. Stone GW, Witzenbichler B, Guagliumi G, Peruga JZ, Brodie BR, Dudek D, et al. Bivalirudin during primary PCI in acute myocardial infarction. N Engl J Med. 2008;358(21):2218-30.

30. Wiviott SD, Braunwald E, McCabe $\mathrm{CH}$, Montalescot G, Ruzyllo W, Gottlieb S, et al. Prasugrel versus clopidogrel in patients with acute coronary syndromes. N Engl J Med. 2007;357(20):2001-155.

31. Giustino G, Harari R, Baber U, Sartori S, Stone GW, Leon $\mathrm{MB}$, et al. Long-term safety and efficacy of new-generation drug-eluting stents in women with acute myocardial infarction: from the Women in
Innovation and Drug-Eluting Stents (WIN-DES) Collaboration. JAMA Cardiol. 2017;2(8):855-62.

32. Giustino G, Mastoris I, Baber U, Sartori S, Stone $\mathrm{GW}$, Leon $\mathrm{MB}$, et al. Correlates and impact of coronary artery calcifications in women undergoing percutaneous coronary intervention with drugeluting stents: from the Women in Innovation and Drug-Eluting Stents (WIN-DES) Collaboration. JACC Cardiovasc Interv. 2016;9(18):1890-901.

33. Shah SR, Fatima M, Dharani AM, Shahnawaz W, Shah SA. Bioresorbable vascular scaffold versus metallic stent in percutaneous coronary intervention: results of the AIDA trial. J Community Hosp Intern Med Perspect. 2017;7(5):307-8.

34. Byrne RA, Joner M, Kastrati A. Stent thrombosis and restenosis: what have we learned and where are we going? The Andreas Gruntzig Lecture ESC 2014. Eur Heart J. 2015;36(47):3320-31.

35. Macaya F, Peral V, Alameda M, Pascual M, GomezJaume A, Asmarats L, et al. Bioresorbable scaffolds to treat spontaneous coronary artery dissection. Circ Cardiovasc Interv. 2016;9(1):e003133.

36. Thourani VH, Kodali S, Makkar RR, Herrmann HC, Williams M, Babaliaros V, et al. Transcatheter aortic valve replacement versus surgical valve replacement in intermediate-risk patients: a propensity score analysis. Lancet. 2016;387(10034):2218-25.

37. Heer T, Hochadel M, Schmidt K, Mehilli J, Zahn R, Kuck $\mathrm{KH}$, et al. Sex differences in percutaneous coronary intervention-insights from the Coronary Angiography and PCI Registry of the German Society of Cardiology. J Am Heart Assoc. 2017;6(3): e004972.

38. Gul B, Shah T, Head SJ, Chieffo A, Hu X, Li F, et al. Revascularization options for females with multivessel coronary artery disease: a meta-analysis of randomized controlled trials. JACC Cardiovasc Interv. 2020;13:1009-100.

39. Sharma V, Jadhav ST, Harcombe AA, Kelly PA, Mozid A, Bagnall A, et al. Impact of proctoring on success rates for percutaneous revascularisation of coronary chronic total occlusions. Open Heart. 2015;2(1):e000228.

40. Mannem S, Rattanawong P, Riangwiwat T, Vutthikraivit W, Putthapiban P, Sukhumthammarat W, et al. Sex difference and outcome after percutaneous intervention in patients with chronic total occlusion: a systematic review and meta-analysis. Cardiovasc Revasc Med. 2020;21(1):25-31.

41. Osnabrugge RL, Mylotte D, Head SJ, Van Mieghem NM, Nkomo VT, LeReun CM, et al. Aortic stenosis in the elderly: disease prevalence and number of 
candidates for transcatheter aortic valve replacement: a meta-analysis and modeling study. J Am Coll Cardiol. 2013;62(11):1002-12.

42. Carabello BA, Paulus WJ. Aortic stenosis. Lancet. 2009;373(9667):956-66.

43. Simard L, Cote N, Dagenais F, Mathieu P, Couture C, Trahan S, et al. Sex-related discordance between aortic valve calcification and hemodynamic severity of aortic stenosis: is valvular fibrosis the explanation? Circ Res. 2017;120(4):681-91.

44. Williams M, Kodali SK, Hahn RT, Humphries KH, Nkomo VT, Cohen DJ, et al. Sex-related differences in outcomes after transcatheter or surgical aortic valve replacement in patients with severe aortic stenosis: Insights from the PARTNER Trial (Placement of Aortic Transcatheter Valve). J Am Coll Cardiol. 2014;63(15):1522-8.

45. Bach DS, Radeva JI, Birnbaum HG, Fournier AA, Tuttle EG. Prevalence, referral patterns, testing, and surgery in aortic valve disease: leaving women and elderly patients behind? J Heart Valve Dis. 2007;16(4):362-9.

46. Elhmidi Y, Piazza N, Mazzitelli D, Wottke M, Lange R, Bleiziffer S. Sex-related differences in 2197 patients undergoing isolated surgical aortic valve replacement. J Card Surg. 2014;29(6):772-8.

47. Kulik A, Lam BK, Rubens FD, Hendry PJ, Masters RG, Goldstein W, et al. Gender differences in the long-term outcomes after valve replacement surgery. Heart. 2009;95(4):318-26.

48. Stewart BF, Siscovick D, Lind BK, Gardin JM, Gottdiener JS, Smith VE, et al. Clinical factors associated with calcific aortic valve disease. Cardiovascular Health Study. J Am Coll Cardiol. 1997;29(3):630-4.

49. Eggebrecht $H$, Bestehorn $M$, Haude $M$, Schmermund A, Bestehorn K, Voigtlander T, et al. Outcomes of transfemoral transcatheter aortic valve implantation at hospitals with and without on-site cardiac surgery department: insights from the prospective German aortic valve replacement quality assurance registry (AQUA) in 17919 patients. Eur Heart J. 2016;37(28):2240-8.

50. Holmes DR Jr, Brennan JM, Rumsfeld JS, Dai D, O'Brien SM, Vemulapalli S, et al. Clinical outcomes at 1 year following transcatheter aortic valve replacement. JAMA. 2015;313(10):1019-28.

51. Vlastra W, Chandrasekhar J, Garcia Del Blanco B, Tchetche D, de Brito FS Jr., Barbanti M, et al. Sex differences in transfemoral transcatheter aortic valve replacement. J Am Coll Cardiol. 2019;74(22): 2758-67.
52. Naoum C, Blanke P, Dvir D, Pibarot P, Humphries $\mathrm{K}$, Webb J, et al. Clinical outcomes and imaging findings in women undergoing TAVR. JACC Cardiovasc Imaging. 2016;9(4):483-93.

53. Buellesfeld L, Stortecky S, Kalesan B, Gloekler S, Khattab AA, Nietlispach F, et al. Aortic root dimensions among patients with severe aortic stenosis undergoing transcatheter aortic valve replacement. JACC Cardiovasc Interv. 2013;6(1): 72-83.

54. Barbanti M, Yang TH, Rodes Cabau J, Tamburino C, Wood DA, Jilaihawi H, et al. Anatomical and procedural features associated with aortic root rupture during balloon-expandable transcatheter aortic valve replacement. Circulation. 2013;128(3): 244-53.

55. Mihos CG, Klassen SL, Yucel E. Sex-specific considerations in women with aortic stenosis and outcomes after transcatheter aortic valve replacement. Curr Treat Options Cardiovasc Med. 2018;20(7):52.

56. Popma JJ, Deeb GM, Yakubov SJ, Mumtaz M, Gada $\mathrm{H}$, O'Hair D, et al. Transcatheter aortic-valve replacement with a self-expanding valve in low-risk patients. N Engl J Med. 2019;380(18):1706-15.

57. Ewe SH, Muratori M, Delgado V, Pepi M, Tamborini G, Fusini L, et al. Hemodynamic and clinical impact of patient-prosthesis mismatch after transcatheter aortic valve implantation. J Am Coll Cardiol. 2011;58(18):1910-8.

58. Ribeiro HB, Webb JG, Makkar RR, Cohen MG, Kapadia SR, Kodali S, et al. Predictive factors, management, and clinical outcomes of coronary obstruction following transcatheter aortic valve implantation: insights from a large multicenter registry. J Am Coll Cardiol. 2013;62(17):1552-62.

59. Azarbaijani Y, O'Callaghan K, Sanders WE, Wu C, Laschinger J, Marinac-Dabic D, et al. Sex-specific outcomes after transcatheter aortic valve replacement: a review of the literature. Cardiol Rev. 2018;26(2):73-81.

60. Saito Y, Nazif T, Baumbach A, Tchetche D, Latib A, Kaple R, et al. Adjunctive antithrombotic therapy for patients with aortic stenosis undergoing transcatheter aortic valve replacement. JAMA Cardiol. 2020;5(1):92-101.

61. Conrotto F, D'Ascenzo F, Presbitero P, Humphries $\mathrm{KH}$, Webb JG, O'Connor SA, et al. Effect of gender after transcatheter aortic valve implantation: a meta-analysis. Ann Thorac Surg. 2015;99(3): 809-16.

62. Flaherty MP, Grubb KJ. Transcatheter aortic valve replacement: focus on sex-related differences in 
outcomes. Am J Cardiovasc Drugs. 2015;15(2): 95-101.

63. Mack MJ, Leon MB, Thourani VH, Makkar R, Kodali SK, Russo $M$, et al. Transcatheter aortic-valve replacement with a balloon-expandable valve in low-risk patients. N Engl J Med. 2019;380(18): 1695-705.

64. Chieffo A, Petronio AS, Mehilli J, Chandrasekhar J, Sartori S, Lefevre T, et al. Acute and 30-day outcomes in women after TAVR: results from the WINTAVI (Women's INternational Transcatheter Aortic Valve Implantation) Real-World Registry. JACC Cardiovasc Interv. 2016;9(15):1589-600.

65. Park K, Wu P, Gulati M. Obstetrics and gynecological history: a missed opportunity for cardiovascular risk assessment. JACC Case Rep. 2020;2(1):161-3.

66. Merk DR, Emrich FC, Mohr FW, Seeburger J. Transcatheter mitral valve repair: where are we? Expert Rev Cardiovasc Ther. 2014;12(12):1379-81.

67. Gammie JS, Sheng S, Griffith BP, Peterson ED, Rankin JS, O'Brien SM, et al. Trends in mitral valve surgery in the United States: results from the Society of Thoracic Surgeons Adult Cardiac Surgery Database. Ann Thorac Surg. 2009;87(5):1431-7 (discussion 37-9).

68. Thourani VH, Weintraub WS, Guyton RA, Jones EL, Williams WH, Elkabbani S, et al. Outcomes and long-term survival for patients undergoing mitral valve repair versus replacement: effect of age and concomitant coronary artery bypass grafting. Circulation. 2003;108(3):298-304.

69. Akins CW, Hilgenberg AD, Buckley MJ, Vlahakes GJ, Torchiana DF, Daggett WM, et al. Mitral valve reconstruction versus replacement for degenerative or ischemic mitral regurgitation. Ann Thorac Surg. 1994;58(3):668-75 (discussion 75-6).

70. Cohn LH, Kowalker W, Bhatia S, DiSesa VJ, St JohnSutton M, Shemin RJ, et al. Comparative morbidity of mitral valve repair versus replacement for mitral regurgitation with and without coronary artery disease. 1988. Updated in 1995. Ann Thorac Surg. 1995;60(5):1452-3.

71. Craver JM, Cohen C, Weintraub WS. Case-matched comparison of mitral valve replacement and repair. Ann Thorac Surg. 1990;49(6):964-9.

72. Enriquez-Sarano M, Schaff HV, Orszulak TA, Tajik AJ, Bailey KR, Frye RL. Valve repair improves the outcome of surgery for mitral regurgitation. A multivariate analysis. Circulation. 1995;91(4): 1022-8.
73. Silvestry FE, Rodriguez LL, Herrmann HC, Rohatgi S, Weiss SJ, Stewart WJ, et al. Echocardiographic guidance and assessment of percutaneous repair for mitral regurgitation with the Evalve MitraClip: lessons learned from EVEREST I. J Am Soc Echocardiogr. 2007;20(10):1131-40.

74. Feldman T, Kar S, Elmariah S, Smart SC, Trento A, Siegel RJ, et al. Randomized comparison of percutaneous repair and surgery for mitral regurgitation: 5-year results of EVEREST II. J Am Coll Cardiol. 2015;66(25):2844-54.

75. Stone GW, Lindenfeld J, Abraham WT, Kar S, Lim DS, Mishell JM, et al. Transcatheter mitral-valve repair in patients with heart failure. $\mathrm{N}$ Engl J Med. 2018;379(24):2307-18.

76. Obadia JF, Messika-Zeitoun D, Leurent G, Iung B, Bonnet G, Piriou N, et al. Percutaneous repair or medical treatment for secondary mitral regurgitation. N Engl J Med. 2018;379(24):2297-306.

77. Gafoor S, Sievert H, Maisano F, Baldus S, Schaefer U, Hausleiter J, et al. Gender in the ACCESS-EU registry: a prospective, multicentre, non-randomised post-market approval study of MitraClip(R) therapy in Europe. EuroIntervention. 2016;12(2): e257-e264264.

78. Maisano F, Franzen O, Baldus S, Schafer U, Hausleiter J, Butter $\mathrm{C}$, et al. Percutaneous mitral valve interventions in the real world: early and 1-year results from the ACCESS-EU, a prospective, multicenter, nonrandomized post-approval study of the MitraClip therapy in Europe. J Am Coll Cardiol. 2013;62(12):1052-61.

79. Geis NA, Puls M, Lubos E, Zuern CS, Franke J, Schueler R, et al. Safety and efficacy of MitraClip therapy in patients with severely impaired left ventricular ejection fraction: results from the German transcatheter mitral valve interventions (TRAMI) registry. Eur J Heart Fail. 2018;20(3): 598-608.

80. Pighi M, Estevez-Loureiro R, Maisano F, Ussia GP, Dall'Ara G, Franzen $\mathrm{O}$, et al. Immediate and 12-month outcomes of ischemic versus nonischemic functional mitral regurgitation in patients treated with MitraClip (from the 2011 to 2012 Pilot Sentinel Registry of Percutaneous Edge-To-Edge Mitral Valve Repair of the European Society of Cardiology). Am J Cardiol. 2017;119(4):630-7.

81. Attizzani GF, Ohno Y, Capodanno D, Cannata S, Dipasqua F, Imme S, et al. Gender-related clinical and echocardiographic outcomes at 30-day and 12-month follow-up after MitraClip implantation in the GRASP registry. Catheter Cardiovasc Interv. 2015;85(5):889-97. 
82. Giustino G, Overbey J, Taylor D, Ailawadi G, Kirkwood K, DeRose J, et al. Sex-based differences in outcomes after mitral valve surgery for severe ischemic mitral regurgitation: from the Cardiothoracic Surgical Trials Network. JACC Heart Fail. 2019;7(6):481-90.
83. Szerlip M. Transcatheter aortic valve replacement: only one of the advantages of being female. J Am Coll Cardiol. 2016;68(25):2745-6. 